\title{
REVIEW
}

\section{Dental disease in children with chronic illness}

\author{
H Foster, J Fitzgerald
}

Arch Dis Child 2005;90:703-708. doi: 10.1136/adc.2004.058065

This article aims to raise awareness among paediatricians and specialist paediatric services that poor oral health, in particular children with chronic illness, is a major cause of morbidity and can be a risk factor for severe, even life threatening complications. Good oral health and dentition is important for efficient mastication, speaking and of course, cosmetically for smiling. If left untreated, dental caries can lead to pain and infection. Chronic infection around one or more teeth can result in damage to localised structures, such as the developing permanent teeth. Children who are medically compromised (such as being immunocompromised from disease and/or therapy) however are at increased risk of developing systemic complications from dental infections, which may prove fatal.

We focus on the role of the general paediatrician in promoting the importance of good dental health for all children and in particular those children "at risk". We present preventive measures, evidence based where available, that may improve dental care and promote the role of paediatric dental services in the multidisciplinary management of chronic disease.

See end of article for authors' affiliations

Correspondence to: Dr H Foster, SCMS (Rheumatology), 4th Floor, Catherine Cookson Building, Medical School, Framlington Place,

Newcastle upon Tyne NE2 $4 \mathrm{HH}$, UK; h.e.foster@nd. ac.uk

Accepted 21 January 2005 and reforms ove are many bacteria in dental plaque, but the most important in the aetiology of dental caries are Streptococcus mutans and lactobacilli. These bacteria metabolise sugars to generate local concentrations of organic acid in the inner layers of plaque on the tooth surface, which lowers the $\mathrm{pH}$ at the tooth surface. When the $\mathrm{pH}$ at the tooth surface falls, a process of demineralisation occurs and calcium and phosphates diffuse out of the tooth enamel. When the $\mathrm{pH}$ at the tooth surface rises again this process is reversed and remineralisation occurs. However, if demineralisation of time in a susceptible tooth, sub-surface softening of the enamel occurs. If the lesion progresses this is followed by "cavitation", forming a carious cavity (fig 1). Caries development is more likely at inaccessible areas where plaque is undisturbed and is worse in children with malocclusion and crowding of teeth. The mean time for caries to be confined to the enamel radiographically varies considerably but a mean of 3-4 years has been suggested. Progression is faster however in high caries risk individuals (as discussed below). Dental erosion (tooth surface loss), differs from dental caries; erosion results from the enamel of the tooth being attacked by acid which may have been ingested but possibly due to reflux. Erosion in 616 year olds is often seen in combination with high consumption of fizzy drinks and fruit juices ${ }^{1}$ (fig 2).

Periodontal disease broadly consists of two elements, gingivitis and periodontitis. Gingivitis is an inflammatory response of the gums (gingivae) to plaque and is present in most mouths and characterised by redness, swelling and bleeding (on probing) of the gingivae (fig 3 ). Although gingivitis is readily reversible with effective plaque control (toothbrushing, flossing, mouthwashes), it may be a precursor of chronic periodontitis, which is the irreversible progression of infection and inflammation of the gingivae, periodontal ligament (which anchors tooth in

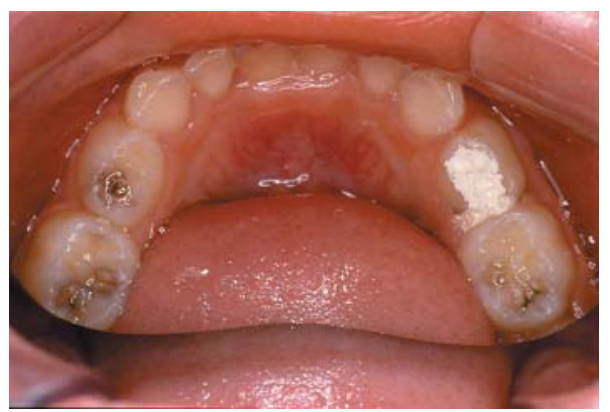

Figure 1 Caries within primary molars. predominates over remineralisation over a period
Figure 2 Enamel erosions induced by high intake of fizzy drinks.

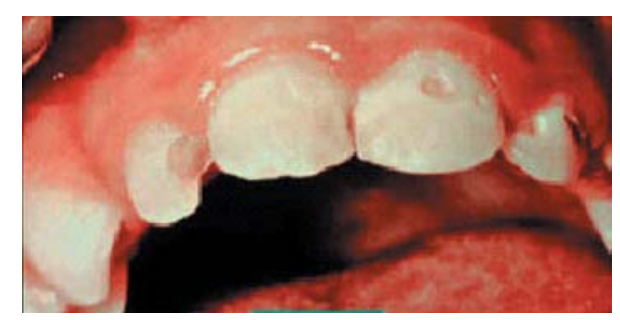




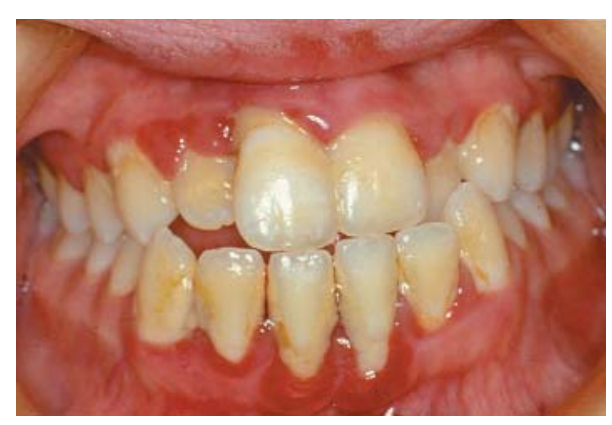

Figure 3 Chronic periodontal disease.

bone), and bone, causing destruction of the periodontium and loss of the tooth.

In summary, caries is a dynamic process which in the early stages of demineralisation can be reversed. Plaque can be removed through good dental hygiene involving toothbrushing, flossing, and mouthwashes. However, if there is a net loss of tooth substance then irreversible cavitation occurs, the surrounding tissues become inflamed (periodontitis), infection may occur, and ultimately there is tooth loss.

\section{HOW IS ORAL HEALTH MEASURED?}

Dental survey programmes involve visual examination by specially trained and calibrated dentists. A mirror and blunt probe are used but no radiographs are taken and thus the surveys are likely to underestimate caries experience. Caries prevalence may be expressed as the proportion of children with active decay and caries severity may be expressed as the number of teeth affected by decay. There are also indices of gingival health (gingival index), plaque (plaque index), and oral cleanliness (oral cleanliness index) ${ }^{2-4}$ However, for large epidemiological studies the DMFT (Decayed, Missing, Filled Teeth) index is a validated index of decay experience. ${ }^{5}$ This index is a measure of the current decay experience (Decayed element), previous decay experience (Missing and Filled elements)—excluding tooth removal for other reasons and can be applied to both the adult (permanent) dentition and milk "baby" (deciduous) dentition, the latter being called the dmft index.

\section{HOW COMMON IS DENTAL CARIES?}

Dental caries and periodontal disease remain the commonest chronic diseases in children in the UK. Fluoride is the most important caries protective agent; the levels of decay fell rapidly after the 1970s when fluoridated toothpaste was introduced ${ }^{6}$ The 2003 Children's Dental Survey ${ }^{7}$ showed that dental decay in 8,12 , and 15 year olds has decreased since 1983. ${ }^{8}$ Despite these trends for improvement, the prevalence of caries in children remains unacceptably high. A survey in 1993 indicated that only 54\% of UK 5 year old children had no decay experience ${ }^{910}$ and this had not significantly fallen in subsequent surveys. ${ }^{11}$ The prevalence of caries varies geographically in the UK; the proportion of 5 year old children with any known decay experience being highest in Northern Ireland $(60 \%)$, followed by Scotland $(55 \%)$, Wales $(51 \%)$, and England (43\%). ${ }^{11}$ Millions of children continue to experience caries, periodontal (gum) disease, tooth loss, and malocclusions (crowding), most of which could be prevented with daily oral hygiene practices and professional care on a scheduled basis. Recently there has been increasing concern that children's dental health in the UK is at risk of further deterioration with the paucity of NHS dentists. In some areas of the UK, two thirds of children (and adults) are not registered with a dentist. ${ }^{7}$

\section{WHAT CAUSES CARIES?}

Caries is multifactorial and risk factors are summarised in table 1. Risk factors include socioeconomic, fluoride experience, medication, dietary habits, abnormal salivary flow and quality, the presence of chronic disease, and oral hygiene techniques (especially where there are difficulties in maintaining good oral hygiene, such as tooth overcrowding and malocclusion).

The evidence that sugar causes dental caries is widely accepted. ${ }^{12}$ Within a few minutes of ingesting sugar, the $\mathrm{pH}$ at the surface of the tooth falls and may take between 20 minutes and several hours to fully recover. The length of time it takes for the tooth surface $\mathrm{pH}$ to return above the critical level (at which demineralisation occurs) depends on the quantity and "stickiness" of the sugar intake. If further sugary loads are taken before the $\mathrm{pH}$ at the tooth surface recovers, prolonged demineralisation occurs. The greater the number of sugary snacks in a day, the more likely caries is to occur. Children with chronic disease often receive small, frequent, low residue meals and frequent sweet treats given by well meaning relatives. Confectionery is the largest source of sugar consumption in the UK followed by soft drinks and table sugar. Studies in young children, older children, and adults show positive correlations between confectionery intake and decay. ${ }^{12}{ }^{13}$ In the younger age group fruit flavoured drinks have been a major cause of caries in infants. These drinks are commonly given to very young children and infants in bottles and feeder cups. As a result extensive caries in the anterior deciduous teeth (often called rampant caries) has affected many children (fig 4). Rampant caries is a

Table 1 Risk factors for caries in children

\begin{tabular}{|c|c|c|}
\hline & Low risk & High risk \\
\hline Socioeconomic & $\begin{array}{l}\text { Mother's education: secondary, tertiary } \\
\text { Good attendance pattern } \\
\text { Family: nuclear, higher social class (I, II, III), employment }\end{array}$ & $\begin{array}{l}\text { Mother's education: secondary } \\
\text { Poor attendance pattern } \\
\text { Family: single parent, social deprivation, unemployment }\end{array}$ \\
\hline General health & Good general health & Chronic illness \\
\hline Medication & No sugar containing medication & Sugar containing medication \\
\hline Oral hygiene & $\begin{array}{l}\text { Regular brushing twice per day with assistance } \\
\text { Good oral hygiene }\end{array}$ & $\begin{array}{l}\text { Irregular brushing without assistance } \\
\text { Poor oral hygiene }\end{array}$ \\
\hline & Less than 3 sugary intakes/day & 3 or more sugar intakes per day \\
\hline Fluoride experience & Regular brushing with fluoride toothpaste & Irregular brushing with fluoride toothpaste \\
\hline \multirow{4}{*}{ Past caries experience } & $\begin{array}{l}\text { Optimally fluoridated water supply } \\
\text { dmft/DMFT less } \leqslant 1\end{array}$ & $\begin{array}{l}\text { No fluoridated water supply } \\
d m f t / D M F T ~ \geqslant 5\end{array}$ \\
\hline & No initial lesions & $\geqslant 10$ initial lesions \\
\hline & Caries free molars at $6-8$ y of age & Caries in first permanent molars at 6 y of age \\
\hline & $\begin{array}{l}3 \text { year caries increment }<3 \\
\text { No appliance therapy }\end{array}$ & $\begin{array}{l}3 \text { year caries increment greater } \geqslant 3 \\
\text { Fixed appliance therapy }\end{array}$ \\
\hline
\end{tabular}




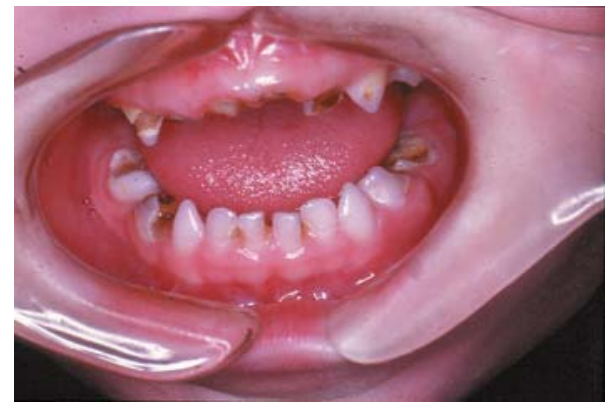

Figure 4 Caries in primary teeth (rampant caries).

disease of deprivation which is frequently more extensive in inner city areas and in children from a lower socioeconomic background or minority ethnic background. ${ }^{13}$

Saliva acts to prevent dental caries in several ways, including a buffering effect which alters the plaque $\mathrm{pH}$, washing away plaque and food debris, an antibacterial action, and contains a reservoir of minerals such as calcium, phosphates, and, under certain circumstances, fluoride. Certain foodstuffs, for example, cheese and sugar-free gum cause the stimulation of salivary flow. Abnormal saliva (quality or quantity), from disease or treatment can increase the caries risk. For example, xerostomia (dry mouth) can be caused by drugs such as anticholinergics and tricyclic antidepressants, disease such as diabetes mellitus and ectodermal dysplasia, and may occur following radiotherapy where such patients are at risk of rampant caries. Xerostomia as a result of Sjögrens's syndrome (an autoimmune disease) is rare in children.

Medications have a marked effect on caries risk. Sugar based syrups are often used as alternatives to tablets in younger children to increase palatability and patient acceptance. ${ }^{14-16}$ There is clear association between sugar containing oral medicines and dental caries and the effect may be greater if they are taken at night or at bedtime when the protective buffering and cleansing effects of saliva are reduced as the salivary flow rate falls. Sugar-free medicines are defined as oral liquid preparations that do not contain fructose, glucose, or sucrose. Prescription of sugar-free medication is particularly important if treatment is long term (defined as daily or alternate days for more than three months). Many of the children receiving long term medication are medically compromised, deemed high caries risk by way of their underlying disease/learning disabilities, and their dental treatment is associated with increased difficulty. Children with conditions such as congenital heart disease, acute lymphoblastic leukaemia, epilepsy, cystic fibrosis, juvenile idiopathic arthritis (JIA), and chronic renal failure, are often taking long term oral medication with liquid or syrup preparations. ${ }^{14-20}$

It is recommended that sugar-free preparations (or tablets for the older child) be used wherever possible. ${ }^{21}$ There are now sugar-free alternatives to most commonly used liquid medicines, including most common antibiotics, anticonvulsants, cough medicines, certain non-steroidal anti-inflammatory drugs (NSAIDs), and paracetamol mixtures. It is noteworthy that many "over the counter medicines" such as cough mixtures are high in sugar content, as is simple linctus which is frequently prescribed. In many cases the sugar-free alternative is the same price as the sugared preparation or only marginally more expensive. In children with musculoskeletal problems, NSAIDs are often prescribed for long periods of time. In addition to the problem with sugar loaded syrups, they may also cause soft tissue ulceration and

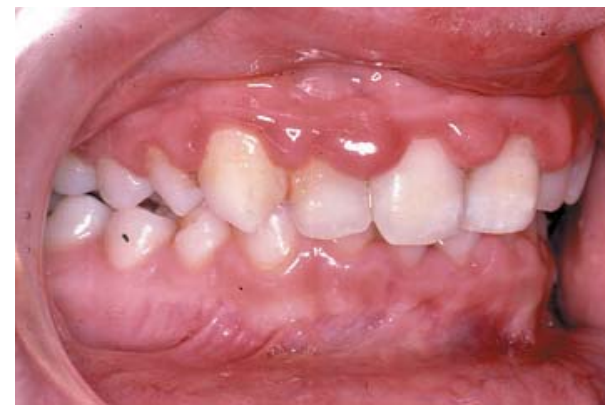

Figure 5 Gingival overgrowth secondary to ciclosporin use.

erosions of the tooth surface if they are not chewed and not swallowed. ${ }^{1}$

Poor oral health is a risk factor for candidiasis, bacteraemia, and potential life threatening septicaemia, especially when the patient is immunosuppressed through use of corticosteroids or other agents such as methotrexate, ciclosporin, or azathioprine. Immunosuppressive therapy is commonly used in many chronic inflammatory diseases such as JIA, connective tissue disease, inflammatory bowel disease, and inflammatory myopathies. Methotrexate and ciclosporin can also cause stomatitis and gingival hyperplasia (fig 5) respectively. More recently novel biological therapies have become available (such as etanercept and infliximab) and increasingly used with proven efficacy in severe polyarticular JIA, ${ }^{22}$ and also are used in other chronic inflammatory diseases. These drugs are potently immunosuppressive and infection is one of the major risks in their use. Inhaled corticosteroids are frequently used as maintenance treatment for asthma and can increase the risk of candidiasis in the otherwise healthy child, the risk being greater in the immunocompromised patient, with the ensuing risk of systemic complications.

The main barriers to attending a dentist include fear, the image of dental practices, dental indifference, and apathy. ${ }^{23}$ Children, but not adults, in the UK have access to free dental care, but in other parts of the world cost may be a barrier to dental care. It is noteworthy that many children with chronic disease continue to have health problems into adolescent and adult years, and their utilisation of dental services as adults may be a considerable burden with the cost becoming a barrier to care. Furthermore, for the child with chronic disease, dental care is often perceived as a low priority. This is supported by evidence that in a survey of children with congenital heart disease, many such children are not registered with a dental practitioner, ${ }^{24}$ and that children with JIA had increased levels of untreated dental disease. ${ }^{25}$

\section{WHO IS THE "HIGH CARIES RISK" CHILD?}

Many chronic diseases in childhood have been associated with poor oral health and increased caries compared to controls. ${ }^{14}$ 17-20 24-34 The prevention of dental disease in children who are medically compromised or who have a learning disability must be recognised as having a "dental special need". Box 1 includes a list of conditions known to be associated with poor oral health and increased caries. Although this list is not comprehensive, it highlights the fact that many chronic disease affecting different systems pose a risk, and furthermore dental treatments may be hazardous. Such children often have several risk factors for poor oral health, including social disadvantage, long term exposure to sugar loaded medicines, and the fact that their dietary habits may not be optimal. Some children may have learning disabilities, and/or anxieties about medical/dental 


\section{Box 1: The child at "high caries risk"; some examples}

Chronic disease

- Structural congenital heart disease

- Bleeding diatheses (e.g. haemophilia)

- Chronic suppurative lung disease (e.g. cystic fibrosis)

- Epilepsy

- Diabetes mellitus

- Juvenile idiopathic arthritis

- Inflammatory bowel disease

- Chronic renal disease

- Immunodeficiency

- Organ transplantation

- Craniofacial abnormalities (e.g. cleft palate)

Learning disabilities

- Down's syndrome

Children in intensive care

- Head injuries

- Burns injuries

Social deprivation

interventions which further compounds the problems. In many cases, preventive dental care for the chronically ill child is not deemed a priority.

It should also be remembered that children with prolonged admission to intensive care units (for example, head injuries, burns, trauma) are at risk of poor oral health, including gingivitis and periodontitis. The oral health changes may well be reversible with resumption of good oral hygiene techniques, but preventive measures are clearly advantageous in preventing systemic complications of bacteraemia and caries in the long term.

Congenital heart defects are common (approximately 8 in 1000 live births) and there is an increasing number of children who have undergone successful cardiac surgery. There is strong evidence that untreated dental disease, and the risk of oral bacteraemia is an important aetiological factor in the causation of infective endocarditis, a condition which still carries a high risk of mortality. Studies of decay in children with congenital heart disease have shown a higher prevalence and severity of decay, compared to controls, ${ }^{24} 29$ and the provision of restorative care was low. ${ }^{24}$ Congenital heart defects may be part of syndromes, such as Down's syndrome, and a disproportionate number of children with heart defects thus have multiple social and learning disabilities, which makes the delivery and acceptance of dental treatment more difficult. Even in children without these additional handicaps, previous medical interventions may make them unduly anxious patients. Children with heart defects should receive maximal preventive dental care, to minimise the need for dental surgical procedures and if procedures are required then appropriate antibiotic cover is required as recommended..$^{35}$ However, of concern, there is evidence from the northeast of England that such children are under-registered with a dentist. ${ }^{24}$

Children with bleeding diatheses may present with bleeding gums, especially after tooth brushing, ${ }^{33}$ and are at risk of chronic periodontal disease. Children may present with acquired bleeding tendencies from malignancy (for example, leukaemia $)^{2728}$ or complications from immunosuppressive regimes. Chemotherapy, radiotherapy, and neutropenia can result in mucositis-that is, painful inflammation and ulceration of the mucous membrane, which renders the child at risk of chronic periodontal disease, caries, and infection (including candidiasis, invasive fungal, viral, and bacterial infections), which can become systemic and life threatening. Treatment, especially radiotherapy, may result in salivary gland dysfunction and xerostomia with resulting rampant caries. Furthermore, long term use of sugar loaded medication adds to the caries risk, and depending on the age of the child at the time of the cancer treatment, developmental defects of the teeth may occur, ${ }^{36}$ which can adversely affect the child's quality of life. Children with haemophilia and malignancy, however, receive dental care as an integral part of their care, often in regional centres; this may explain why the reported incidence of caries in these patients is in fact lower than in controls. ${ }^{31-33}$

Several studies of children with learning difficulties have shown increased markedly increase levels of caries and furthermore, increased levels of untreated decay, which suggests barriers to care. It is noteworthy that many of these children, especially those with Down's syndrome, have congenital heart disease. ${ }^{37-39}$

Children with physical disabilities are also at high risk of caries. Juvenile idiopathic arthritis (JIA) is the commonest cause of disability in children. We have recently reported increased rates of caries, at all ages, and furthermore increased levels of untreated disease, which again suggests barriers to care. $^{25}$ The explanation is likely to be multifactorial, including salivary abnormalities, ${ }^{40}$ sugar loaded syrups, dietary habits, upper limb disability and difficulties with using a toothbrush effectively, malocclusion/tooth overcrowding, and abnormal jaw opening due to temporomandibular disease (TMJ). ${ }^{20}$ Children with JIA are also reported to have increased enamel defects. ${ }^{41}$ Where dental treatment is required, intubation and airway maintenance may be difficult because of micrognathia or cervical spine disease.

\section{WHAT CAN BE DONE TO PREVENT CARIES?}

The need to improve the dental health of all children is paramount ${ }^{42-45}$ and is recognised as a global public health concern. ${ }^{46}$ The general paediatrician, and allied health professionals involved in the care of children can play an important role in the prevention of caries in all children and especially those with chronic disease with whom they are more likely to have regular contact. Box 2 summarises the preventive measures that can be taken to reduce caries in the high risk child; ${ }^{42}$ the general paediatrician and allied health professionals can reinforce this advice and also directly influence the prescription of sugar-free medication. It is imperative that high caries risk children are identified and that paediatric dental services (which will include the dentist, orthodontist, and hygienist) are involved early in the planning of the multidisciplinary management. The paediatrician can certainly facilitate referral to dental services and emphasise the importance of dental care, compliance with appointments, treatment, and advice. For high caries risk groups it is recommended that regular dental care issues are covered within specialist paediatric services. Prevention of poor oral health and caries is the cornerstone of success of dental management with the aim to minimise operative intervention. The success of integrated dental care is exemplified by the services for haemophilia and cancer, where caries rates for children with haemophilia and who receive regular dental care, are lower than controls. ${ }^{31-33}$ The emphasis of preventive dental care lies on patient and family education, dietary advice, plaque control, fissure sealants, orthodontic treatment, use of topical fluorides, and use of 


\section{Box 2: Prevention of caries in children}

(including recommendations taken from SIGN Guideline ${ }^{42}$ with the level of evidence, based on the SIGN classification, given in parentheses, and of evidence described in Shaw ${ }^{43}$ )

Assessment of the caries risk for each child presenting for dental care [B]

The following factors should be included in this risk assessment [B]:

- Clinical evidence of previous disease

- Dietary habits (especially frequency of sugary food and drink consumption)

- Social history, especially socioeconomic status

- Use of fluoride

- Plaque control (toothbrushing, flossing, mouthwashes)

- Saliva

- Medical history

Behaviour modification in high caries risk children

- Dental health education advice should be provided to individual patients in the chair as this intervention has been shown to be beneficial [A]

- Toothbrushing twice per day using a small pea sized amount of toothpaste that contains at least 1000 ppm fluoride. They should spit the toothpaste out and not rinse out with water [A]

- The need to restrict sugary food and drink consumption to meal times only should be emphasised [B]

- Dietary advice to encourage the use of non-sugar sweeteners (in particular xylitol) in food and drink [B]

- Patients should be encouraged to use sugar-free chewing gum [B]

- Clinicians should prescribe sugar-free medicines whenever possible and recommend use of sugar-free forms of nonprescription medicines [B]

Tooth protection in children at high caries risk

- Sealants should be applied and maintained in the tooth pits/fissures [A]

- For children living in areas with water supplies with less than $0.3 \mathrm{ppm}$ fluoride ion, supplements may be used with careful guidance according to the age of the child

- Fluoride varnishes may be applied every 4-6 months [B]

- Fluoride tablets (1 mg fluoride/day) for daily sucking should be considered for children at high risk of decay [B]

- Low sugar artificial saliva and/or sugar-free chewing gum should be considered for patients with dry mouth

sugar-free medicines wherever possible. Patients should be particularly advised to decrease both the quantity and frequency of their sugar intake; in particular they should avoid sugary snacks between meals and immediately before bedtime. Paediatricians need to be aware of the markedly increased risk of dental caries in the presence of dry mouthchewing gum (sugar-free) is advocated to stimulate saliva flow and lubricants and artificial salivas may be helpful. Prevention can also be achieved by effective removal of plaque by diligent brushing and flossing, and tooth strengthening by provision of fluoride and fissure sealants. Tooth brushing with fluoride toothpaste both removes plaque and provides fluoride. It is important to stress that fluoride toothpaste/supplements must be used judiciously to prevent fluorosis (tooth mottling). The wide and effective use of fluoride in toothpaste is the single most effective method of topical caries prevention and is one of the great success stories in preventive medicine. ${ }^{67-48}$

Families of children with congenital heart disease must be aware of the need for antibiotic prophylaxis in the event of dental treatment, and the general paediatrician can reinforce this advice. ${ }^{35}$ For the child with physical disability, the occupational therapist and physiotherapist are involved in the assessment of functional limitation. They can help the child to improve manual dexterity, reduce functional limitation, and improve toothbrushing techniques. Furthermore, for children with JIA or other conditions causing upper limb disability, a powered toothbrush may be helpful in improving oral hygiene, although a reduction in caries risk has yet to be shown. Orthodontic monitoring of growth is advised from an early age, with radiographs where necessary to monitor TMJ changes. Where growth is seen to be disturbed, functional appliances may be indicated to aim for occlusal stability, restoration of function, and uninhibited growth of the mandible.

We recommend to the reader evidence based guidelines of the prevention of caries in children: Prevention of caries in the high risk child, ${ }^{42}$ the UK national clinical guidelines in paediatric dentistry, ${ }^{43}$ and systematic reviews published the Cochrane Oral Health Group which include the role of fluoride, ${ }^{48}$ powered versus manual toothbrushes, ${ }^{49}$ penicillin prophylaxis for children with congenital heart disease, ${ }^{35}$ and fluoridated milk.50 There is a strong evidence base for the use of fluoridated toothpastes and topical fluoride gels, fissure sealants to prevent carie, $\mathrm{s}^{48}$ and penicillin prophylaxis for children with congenital heart disease undergoing dental treatment to prevent endocarditis. ${ }^{35}$ The role of powered toothbrushes is controversial; the Cochrane Oral Health Group concluded that powered toothbrushes do achieve a modest reduction in plaque and gingivitis compared to manual toothbrushing, but further trials in the "at risk" child are required. ${ }^{49}$ Subsidised powered toothbrushes are available for children with chronic arthritis through the Children's Chronic Arthritis Association (www.ccaa.org.uk). Box 2 summaries the preventive measures recommended by the above mentioned guidelines and the evidence based on 
the SIGN classification. ${ }^{42}$ Once caries is detected, there is also guidance, evidence based where possible, on the treatment and secondary prevention. ${ }^{42}$

In summary, caries and poor oral health are common in many children. The risk and potential sequelae of poor oral health and caries are greater in medically compromised children. The provision of preventive dental care is a very important aspect of multidisciplinary management of such children. The general paediatrician plays an important role in raising awareness of the importance of good dental health among all children and their families, encouraging attendance, and facilitating referral of at risk children to paediatric dental services. Early involvement of the paediatric dental services as members of the multidisciplinary team will raise awareness, confidence, and cooperation of children and parents. There is a strong evidence base to support preventive measures for the high risk caries child, and the general paediatrician can facilitate these guidelines being used in clinical practice and ultimately improve the quality of life for these children.

\section{Authors' affiliations \\ H Foster, J Fitzgerald, University of Newcastle, Newcastle-upon-Tyne, UK}

Competing interests: none declared

\section{APPENDIX}

\section{WEBSITES OF INTEREST}

http://www.sign.ac.uk - SIGN Guidelines

http://www.cochrane.uk - Cochrane Database of Systematic Reviews

http://www.bda-dentistry.org.uk - British Dental Association http://www.iapdworld.org - International Association of Paediatric Dentistry

http://www.bsdh.org.uk - British Society for Disability and Oral Health

\section{REFERENCES}

1 Sullivan RE, Kramer WS. latrogenic erosion of teeth. ASDC Journal of Dentistry for Children 1983;50:192-6.

2 Loe $\mathrm{H}$, Silness J. Periodontal disease in pregnancy. I. Prevalence and severity. Acta Odontol Scand 1963;21:533-51.

3 Silness J, Loe H. Periodontal disease in pregnancy. II. Correlation between oral hygiene and periodontal condition. Acta Odontol Scand 1964:22:121-35.

4 Turesky S, Gilmore ND, Glickman I. Reduced plaque formation by the chloromethyl analgue of vitamin C. J Periodontol 1970;41:41-3.

5 Mitropoulos C, Pitts NB, Deery C. British Association for the Study of Community Dentistry criteria for the standardised assessment of dental health. BASCOD trainers pack for caries prevalence. University of Dundee, 1992.

6 Riordan PJ. The place of fluoride supplements in caries prevention today. Aust Dent J 1996;41:335-42.

7 Office of Population, Censuses and Surveys. Children's dental health in the UK 2003. London: Office of Population, Censuses and Surveys, 2004.

8 Todd JE, Dodd T. Children's dental health in the United Kingdom 1983. London: HMSO, 1985

9 Downer MC. Time trends in the caries experience of children in England and Wales. Caries Research 1992;26:466-72.

10 O'Brien M. Children's dental health in the United Kingdom 1993. London: Office of Population, Censuses and Surveys, 1994.

11 Pitts NB, Evans DJ, Nugent Z. The dental caries experience of 14-year-old children in the United Kingdom. Surveys coordinated by the British Association for the Study of Community Dentistry in 1998/99.

12 Winter GB. Epidemiology of dental caries. Arch Oral Biol 1990;35(suppl): 1S-7S.

13 Scottish Dental Practice Board. Annual report 1996/1997. Edinburgh: Scottish Dental Practice Board, Trinity Park House, 1997.

14 Kenny DJ, Somaya P. Sugar load of oral liquid medications on chronically ill children. J Can Dent Assoc 1989;55:43-6.

15 Roberts IF, Roberts GJ. Relation between medicines sweetened with sucrose and dental disease. BMJ 1979;ii:14-16.

16 Maguire A, Rugg-Gunn A. Medicines in liquid and syrup form used long term in paediatrics: a survey in the northern region of England. Int J Paediatr Dent 1994;4:93-9.
17 Roberts GJ, Roberts IF. Dental disease in chronically sick children. ASDC J Dent Child 1981;48:346-51

18 Feigal RJ, Gleeson MC, Beckman TM, et al. Dental caries related to liquid medication intake in young cardiac patients. J Dent Child 1984;51:360-2.

19 Fleming $P$, Kinirons MJ. Dental health of children suffering from acute lymphoblastic leukaemia. J Paediatr Dent 1986;2:1-5.

20 Walton AG, Thomason JM, Welbury RR, et al. Oral health problems in children and adolescents with Juvenile idiopathic Arthritis. Rheumatology 2000;39:550-5.

21 Committee on Medical Aspects of Food and Nutrition Policy. Dietary sugars and human disease. Report of the Panel on Dietary Sugars (Report on Health and Social Subjects No. 37). London: HMSO, 1989.

22 Lovell DJ, Giannini EH, Reiff A, for the Paediatric Rheumatology Collaborative Study group, et al. Etanercept in children with polyarticular juvenile rheumatoid arthritis. N Engl J Med 2000;342:763-9.

23 Finch H, Keegan J, Ward K, et al. Barriers to the receipt of dental care. A qualitative research study January 1998, Social and Community Planning Research, 35 Northampton Square, London ECIV OAX.

24 Lowry LY, Evans DJ, Lowry RJ, et al. Under-registration for dental care of children with heart defects in the north-east of England: a comparative study. Prim Dent Care 1996;3:68-70

25 Welbury RR, Fitzgerald JL, Marshall NM, et al. Increased dental decay and poor oral cleanliness in juvenile idiopathic arthritis. Rheumatology 2003:42: 1445-51.

26 Moore RS, Hobson P. A classification of medically handicapping conditions and the health risks they present in the dental care of children. Parts 1 and 2 . J Paediatr Dent 1989;5:73-83; 1990;6:1-4.

27 Chin EA. A brief overview of the oral complications in paediatric oncology patients and suggested management strategies. ASDC J Dent Child 1998;65:468-73.

28 Collard M, Hunter M. Oral and dental care in acute lymphoblastic leukaemia: a survey of United Kingdom Children's Cancer Study Group centres. Int J Paediatr Dent 2001;11:347-51.

29 Balmer R, Bu'Lock FA. The experiences with oral health and dental prevention of children with congenital heart disease. Cardiol Young 2003; 13:439-43.

30 Kirchberg A, Treide A, Hemprich A. Investigation of caries prevalence in children with cleft lip, alveolus and palate. J Craniomaxillofac Surg 2004;32:216-19.

31 Nunn JH, Welbury RR, Gordon PH, et al. Dental caries and dental anomalies in children treated by chemotherapy for malignant disease: a study in the north of England. Int J Paediatr Dent 1991;1:131-5.

32 Boyd D, Kinirons M. Dental caries experience of children with haemophilia in Northern Ireland. Int J Paediatr Dent 1997:7:149-53.

33 Sonbol H, Pelargidou M, Lucas VS, et al. Dental health indices and caries related microflora in children with severe haemophilia. Haemophilia 2001;7:468-74.

34 Al-Nowaiser A, Roberts GJ, Trompeter RS, et al. Oral health in children with chronic renal failure. Pediatr Nephrol 2003; 18:39-45.

35 Oliver R, Roberts GJ, Hooper L. Penicillins for the prophylaxis of bacterial endocarditis in dentistry. Cochrane Database of Systematic Reviews 2004;2.

36 Maguire A, Craft AW, Evans RG, et al. The long-term effects of treatment on the dental condition of children surviving malignant disease. Cancer 1987;60:2570-5

37 Urquart APM, Blinkhorn AS. The dental health of children with congenital cardiac disease. Scott Med J 1990;35:166-8.

38 Hobson P, Slattery GR. Treatment needs of medically handicapped children in the north district of Manchester. Community Dent Health 1990;1:173-80.

39 Nunn JH. The dental health of mentally and physically handicapped children: a review of the literature. Community Dent Health 1987:4:157-68.

40 Walton AG, Welbury RR, Foster HE, et al. Sialochemistry in juvenile idiopathic arthritis. Oral Diseases 2002;8:287-90.

41 Welbury RR, Thomason JM, Fitzgerald JL, et al. Type and extent of enamel defects in juvenile idiopathic arthritis (JIA). Eur J Paediatr Dent 2002;4: 1-5

42 SIGN. Preventing dental caries in children at high caries risk. Targeted prevention of dental caries in the permanent teeth of 6-16 year olds presenting for dental care. Scottish Intercollegiate Guideline Network (SIGN) Publication No. 47. December 2000 (www.sign.ac.uk/pdf/sign 47)

43 Shaw L. The UK National Guidelines in Paediatric Dentistry. Int J Paediatr Dent 1997:7:267-72.

44 British Association for the Study of Community Dentistry (BASCD). Policy document-oral health promotion. BASCD, 1999.

45 Dept of Health. An oral health strategy of England. London: HMSO, 1994.

46 Petersen PE. The World Oral Health Report 2003: continuous improvement of oral health in the 21 st century - the approach of the WHO Global Oral Health Programme. Community Dent Oral Epidemiol 2003;31:3-23.

47 Marinho VC, Higgins JP, Logan S, et al. Systematic review of controlled trials on the effectiveness of fluoride gels for the prevention of dental caries in children. J Dent Educ 2003;67:448-58.

48 Marinho VC, Higgins JP, Logan S, et al. Topical fluoride (toothpastes, mouthrinses, gels or varnishes) for preventing dental caries in children and adolescents. Cochrane Database of Systematic Reviews 2004;2.

49 Heanue M, Deacon SA, Deery C, et al. Manual versus powered toothbrushing for oral health. Cochrane Database of Systematic Reviews 2004;2.

50 Yeung CA, Tickle M. Fluoridated milk for preventing dental caries in children and adolescents. Cochrane Oral Health Group. Cochrane Database of Systematic Reviews 2004;2. 